\title{
Перспективные сорта и гибриды свеклы столовой для длительного хранения
}

\section{В.А. Борисов, Н.А. Фильрозе, Л.М. Соколова, А.В. Корнев}

В результате пятилетних исследований (2013-2017 годы) выяснено, что наиболее перспективные отечественные сорта для длительного хранения Маришка, Русская односемянная, Фортуна, Деметра, Бордовая ВНИИО, Бордо 237. Среди голландскихгибридов можно выделить $F_{1}$ Пабло и $F_{1}$ Водан. Эти сорта и гибриды в течение 6-7 месяцев хранения имели минимальные потери продукции от убыли массы и болезней при сохранении высокого качества продукции.

Ключевые слова: свекла столовая, сорта, гибриды, хранение, лежкость, качество.

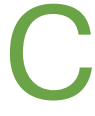
векла столовая входит в основной рацион питания населения Российской Федерации как культура борщевой группы. Она характеризуется высокими питательными и лечебными свойствами благодаря содержанию комплекса витаминов, биологически активных веществ, углеводов, незаменимых аминокислот $[1,2]$. Однако уровень производства свеклы столовой не полностью обеспечивает потребность населения из-за недостаточной урожайности и низкой лежкости заложенной продукции из-за сильного развития болезней при хранении [3]. Одно из важнейших мероприятий решения проблемы хранения свеклы столовой - подбор сортов и гибридов, обладающих высокой болезне- устойчивостью в процессе длительного хранения. Согласно ранее полученным данным [4], при хранении свеклы столовой большое значение имеет сортотип. Убыль массы корнеплодов свеклы в зависимости от сортотипа составляет от 2,9 до 8,1\%, потери от болезней от 1,2 до $18,2 \%$ [6].

Исследования были проведены в 2013-2017 годах на экспериментальной базе и в опытном хранилище ВНИИО - филиала ФГБНУ ФНЦО (Раменский район Московской области). Полевые опыты были заложены на аллювиальных луговых почвах поймы р. Москвы, которые характеризовались нейтральной реакцией среды (pH 6,0-6,5) и высоким содержанием подвижного фосфора, средним уровнем обменного калия и мощным гумусовым горизонтом (до 60-80 см), а содержание гумуса в пахотном слое 3,03,4\%. Эти почвы характерны для овощеводческих хозяйств области и позволяют получать высокий уровень урожая овощных культур.

Сорта и гибриды свеклы столовой выращивали в одинаковых условиях, на фоне расчетных доз минеральных удобрений $\left(\mathrm{N}_{120} \mathrm{P}_{60} \mathrm{~K}_{180}\right)$. Посев столовой свеклы - 18-20 мая с расчетной густотой стояния растений 400-450 тыс. шт/га. В период вегетации проводили междурядные обработки гербицидами, полив растений - согласно принятой в хозяйстве технологии. Уборка - в середине сентября. Стандартную продукцию закладывали на хранение согласно рекомендованным нормативам [5]. Для свеклы столовой оптимальный температурный режим хранения составляет 0-1 ${ }^{\circ} \mathrm{C}$, а влажность воздуха 90-95\%, которые поддерживались в овощехранилище (рис.1). Период хранения корнеплодов в хранилище - 6 месяцев.

В таблице представлены средние показатели со-

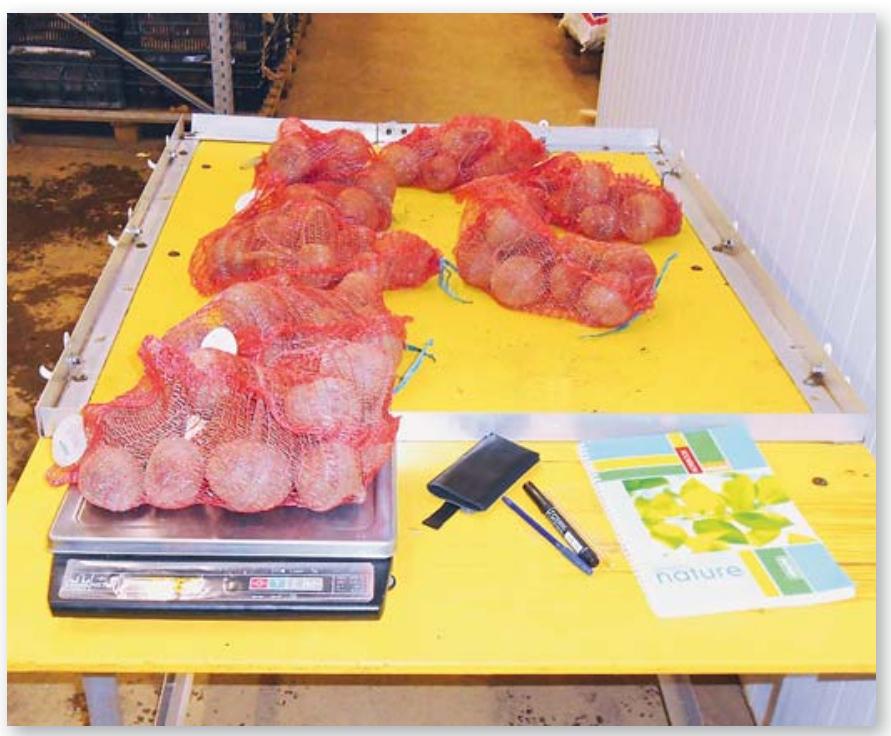

Рис. 1. Учет сохраняемости образцов в хранилище

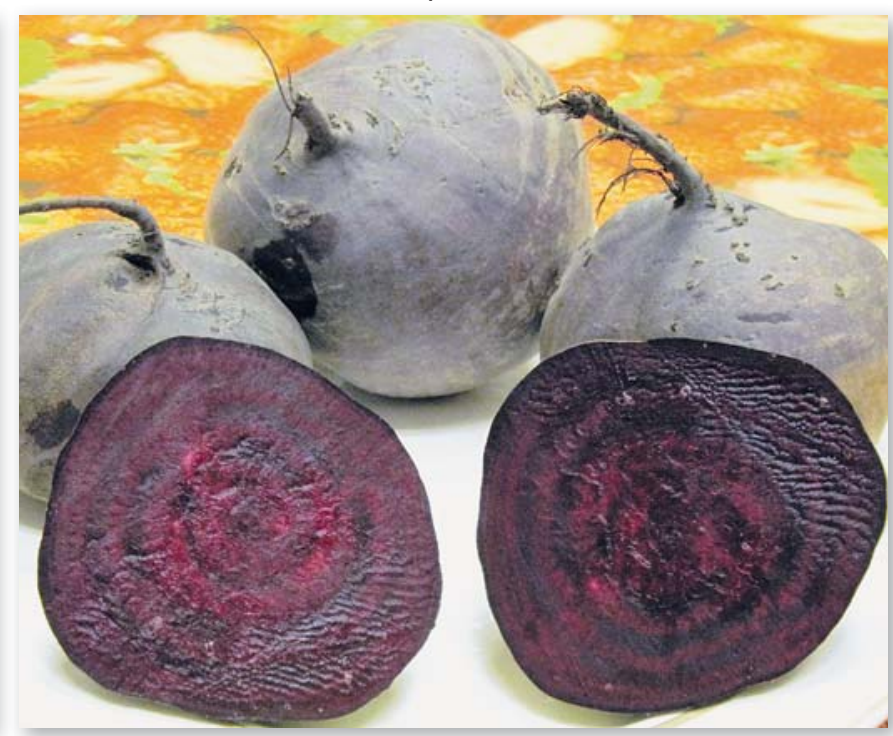

Рис. 2. $F_{1}$ Пабло 
Сохраняемость свеклы столовой сортов отечественной селекции и гибридов голландской селекции, среднее за 2013 - 2017 годы (\% к исходной массе продукции)

\begin{tabular}{|c|c|c|c|c|c|c|c|}
\hline \multirow{3}{*}{ Сорт, гибрид } & \multirow{3}{*}{$\begin{array}{c}\text { Выход } \\
\text { товарной } \\
\text { продукции }\end{array}$} & \multicolumn{6}{|c|}{ Потери } \\
\hline & & \multirow{2}{*}{ всего } & \multirow{2}{*}{ убыль массы } & \multirow{2}{*}{ от болезней } & \multicolumn{3}{|c|}{ по видам болезней } \\
\hline & & & & & белая гниль & серая гниль & фузариоз \\
\hline \multicolumn{8}{|c|}{ Отечественные сорта } \\
\hline Бордо 237 & 89,1 & 10,9 & 8,3 & 2,6 & 0,0 & 0,5 & 2,1 \\
\hline Бордовая ВНИИО & 89,5 & 10,5 & 8,5 & 2,0 & 2,0 & 0,0 & 0,0 \\
\hline Двусемянная ТСХА & 87,1 & 12,9 & 8,8 & 4,1 & 1,6 & 1,1 & 1,4 \\
\hline Детройт & 80,8 & 19,2 & 11,9 & 7,3 & 3,4 & 0,0 & 3,9 \\
\hline Деметра & 89,6 & 10,4 & 10,4 & 0,0 & 0,0 & 0,0 & 0,0 \\
\hline Жуковчанка & 86,5 & 13,5 & 9,1 & 4,4 & 3,6 & 0,0 & 0,8 \\
\hline Карина & 85,0 & 15,0 & 7,9 & 7,1 & 3,9 & 0,0 & 3,2 \\
\hline Маришка & 92,4 & 7,6 & 6,8 & 0,8 & 0,0 & 0,0 & 0,8 \\
\hline Мулатка & 88,0 & 12,0 & 8,5 & 3,5 & 0,8 & 0,0 & 2,7 \\
\hline Одноростковая & 88,2 & 11,8 & 8,9 & 2,9 & 0,5 & 0,3 & 2,1 \\
\hline Русская односемянная & 90,2 & 9,8 & 7,4 & 2,4 & 1,3 & 0,3 & 0,8 \\
\hline Славянка & 88,4 & 11,6 & 9,3 & 2,3 & 0,6 & 0,0 & 1,7 \\
\hline Смуглянка & 84,9 & 15,1 & 10,9 & 4,2 & 1,0 & 1,1 & 2,1 \\
\hline Фортуна & 89,9 & 10,1 & 8,7 & 1,4 & 0,0 & 0,0 & 1,4 \\
\hline \multicolumn{8}{|c|}{ Голландские гибриды } \\
\hline $\mathrm{F}_{1}$ Боро & 82,6 & 17,4 & 7,8 & 9,6 & 4,0 & 0,7 & 4,9 \\
\hline $\mathrm{F}_{1}$ Водан & 87,3 & 12,7 & 8,7 & 4,0 & 1,9 & 0,9 & 1,2 \\
\hline $\mathrm{F}_{1}$ Пабло & 88,8 & 11,2 & 8,6 & 2,6 & 0,0 & 0,6 & 2,0 \\
\hline$F_{1}$ Экшен & 82,1 & 17,9 & 10,8 & 7,1 & 3,1 & 0,1 & 3,9 \\
\hline $\begin{array}{l}\text { Среднее по отечест- } \\
\text { венным сортам }\end{array}$ & 87,8 & 12,2 & 9,0 & 3,2 & 1,3 & 0,3 & 1,6 \\
\hline $\begin{array}{l}\text { Среднее по голланд- } \\
\text { ским гибридам }\end{array}$ & 85,2 & 14,8 & 9,0 & 5,8 & 2,2 & 0,6 & 3,0 \\
\hline
\end{tabular}

храняемости отечественных сортов и голландских гибридов свеклы столовой за 2013-2017 годов.

Результаты оценки сохраняемости свеклы столовой согласно методики Госсортиспытания:
5 баллов (сохраняемость > 95\%) нет сортообразцов;

4 балла (сохраняемость 90-95\%) - Маришка, Русская односемянная;

3 балла (сохраняемость 8090\%) - Фортуна, Деметра, Бордовая
Вниио, Бордо 237, $F_{1}$ Пабло, Славянка, Одноростковая, Мулатка, $\mathrm{F}_{1}$ Водан, Двусемянная ТСХА, Жуковчанка, Карина, Смуглянка, $F_{1}$ Боро, $F_{1}$ Экшен, Детройт;

2 балла (сохраняемость < 80\%) нет сортообразцов.

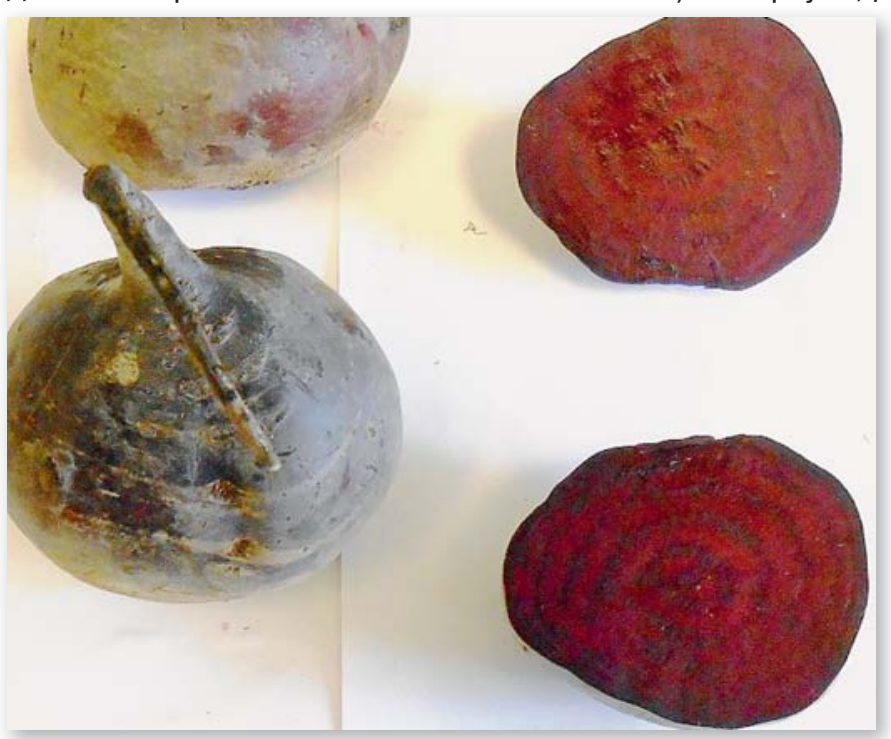

Рис. 3. Деметра

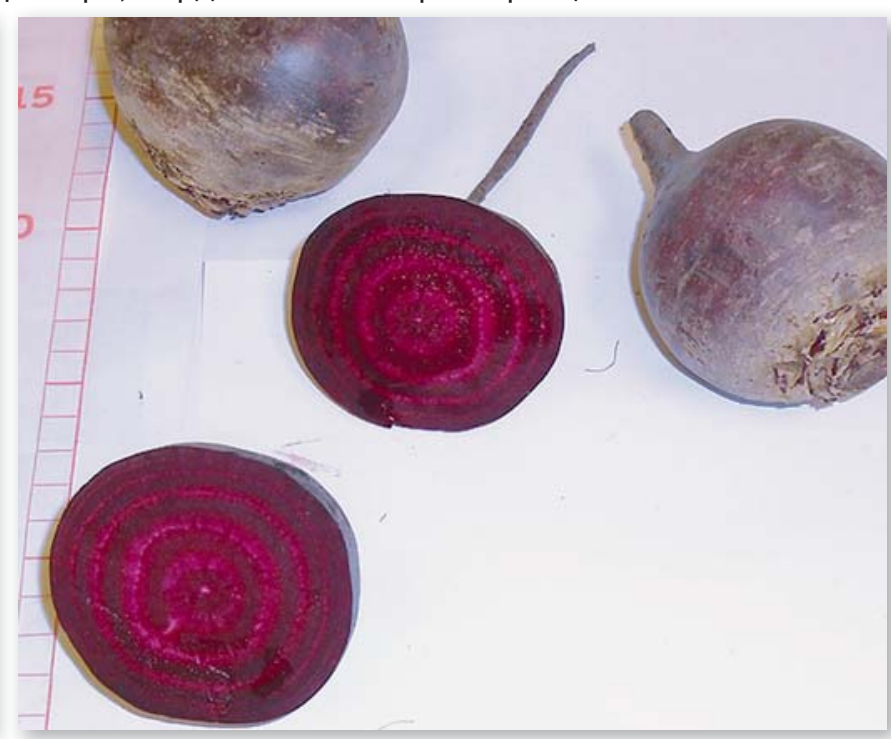

Рис. 4. Русская односемянная 


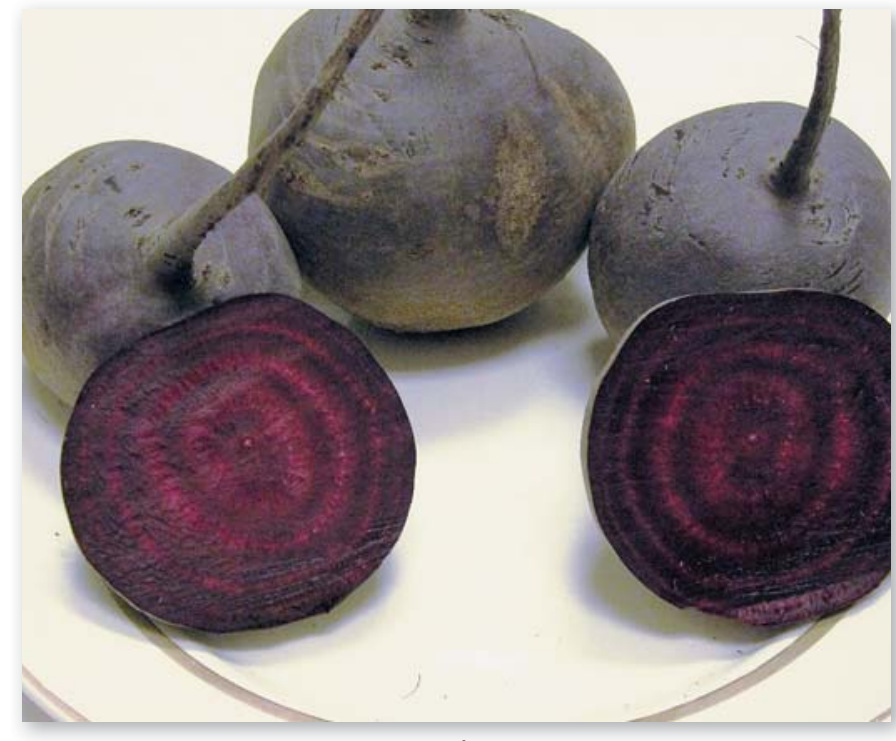

Рис. 5. Фортуна

У сортов Маришка с максимальным выходом товарной продукции 92,4\% среди исследуемых сортообразцов были отмечены лишь поражения фузариозом - 0,8\% и самая низкая убыль массы - 6,8\%. Русская односемянная при выходе стандартной продукции в 90,2\% имела потери от белой гнили - 1,3\%, серая гниль - 0,3\%, фузариоза 0,8\%. Сортам с оценкой в 3 балла: Фортуна, Деметра, Бордовая ВНИИО, Бордо 237 при выходе стандартной продукции 89,9\%, $89,6 \%, 89,5 \%, 89,1 \%$ не хватило совсем немного до $90 \%$ и поэтому их можно тоже потенциально считать как перспективные сорта, близкие к оценке на 4 балла. Сорт Детройт с выходом товарной продукции в 80,8\% - самой низкой среди исследуемых сортообразцов и самой высокой убылью массы в $11,9 \%$, хотя и попал в группу по сохраняемости в «3 балла», но потенциал лежкости его невелик и лишь 0,8\% отде-ляло его от группы «2 балла». У сорта Смуглянка с уплощенным с полюсов формой корнеплода в период хранения проявились многие болезни: белая гниль $1,0 \%$, серая гниль - 1,1\%, фузариоз - 2,1\%. Видимо это связано и с закономерностью, выявленной в предыдущих исследованиях: существует корреляция между скороспелостью и формой корнеплода все сорта с овальной формой более скороспелы, нежели удлиненноовальные. И хотя сорт Смуглянка и показал удовлетворительные ре- зультаты по выходу товарной продукции на $84,9 \%$ (3 балла) все же по своей биологической и генетической особенности, он - скороспелый сорт, поэтому длительное хранение его нецелесообразно. Среди голландских гибридов выделились гибриды $F_{1}$ Пабло и $\mathrm{F}_{1}$ Водан (рис. 2, 3) с выходом товарной продукции $88,8 \%$ и $87,3 \%$ соответственно. Гибриды $F_{1}$ Боро и $\mathrm{F}_{1}$ Экшен показали близкие показатели сохраняемости - 82,6\% и $82,1 \%$. Причем все гибриды, кроме $\mathrm{F}_{1}$ Пабло были поражены целым комплексом болезней.

Большинство изученных сортов свеклы столовой отечественной селекции не уступают по сохраняемости зарубежным гибридам, а сорта: Маришка, Русская односемянная (рис. 4), Фортуна (рис. 5), Деметра, Бордовая ВНИИО, Бордо 237 даже превосходят их. Сравнивая средние показатели по потерям по видам болезней, преимущество отечественных сортов над голландскими гибридами составило: по белой гнили - на 0,9\%, по серой гнили - на $0,3 \%$, по фузариозу - на $1,4 \%$ и в целом по сумме потерей от болезней на $2,6 \%$.

\section{Выводы.}

1. По результатам исследований можно рекомендовать для длительного хранения отечественные сорта: Маришка, Русская односемянная, Фортуна, Деметра, Бордовая ВНИИО, Бордо 237. Среди голландских гибридов можно выделить $\mathrm{F}_{1}$ Пабло и $\mathrm{F}_{1}$ Водан.

2. Лучшей устойчивостью к болезням в период зимнего хранения обладали отечественные сорта свеклы столовой Деметра (0\%), Маришка $(0,8 \%)$, Фортуна $(1,4 \%)$, Бордовая ВНИИО (2,0\%), Славянка (2,3\%), Русская односемянная (2,4\%), Бордо 237 (2,6\%), а из голландских гибридов - F Пабло (2,6\%).

3. Преобладающими болезнями при хранении столовой свеклы у отечественных сортов и зарубежныхгибридов были белая гниль и фузариоз.
Библиографический список

1.Литвинов С.С. Научные основы современного овощеводства. М.: Изд. Россельхозакадемии, 2008. 771 с. 2.Рабинович А.М., Борисов В.А. Целебные свойства овощных и пряноароматических растений России. М.: Арнебия, 2008. 510 c.

3.Литвинов С.С. Шатилов М.В. Эффективность овощеводства России. М.: ВНИИО, 2015. 140 с.

4.Борисов В.А., Литвинов С.С., Романова А.В. Качество и лежкость овощей.М., 2003. 625 с.

5.Методические указания по проведению научноисследовательских работ по хранению овощей. М.: ВАСХНИЛ, 1982. 34 с.

6.Отчет лаборатории хранения отдела земледелия и агрохимии за 2015 год. М.: ВНИиО, 2015. 263 с.

\section{Об авторах}

Борисов Валерий Александрович, доктор с. -х. наук, профессор, г.н.с. отдела земледелия и агрохимии, ВНИИО - филиал ФГБНУ ФНЦО. E-mail: valeri.borisov.39@mail.ru Фильрозе Николай Айтжанович, н.с. лаборатории хранения и земледелия, ВНИИО - филиал ФГБНУ ФНЦО. E-mail: Suburban_Chevrolet@mail.ru Соколова Любовь Михайловна, канд. с. - х. наук, с.н.с. отдела селекции и семеноводства, ВНИИО - филиал ФГБНУ ФНЦО.

E-mail: Isokolova74@mail.ru

Корнев Александр Владимирович, канд. с. - х. наук, н.с. отдела селекции и семеноводства, ВНИИО - филиал ФГБНУ ФНЦО.

E-mail: alexandrvg@gmail.com

Promising varieties and hybrids of beet canteen for long-term storage

V.A. Borisov, DSc, professor, chief research fellow of the department of agriculture and agrochemistry, ARRIVG FSBSI FSVC.

E-mail: valeri.borisov.39@mail.ru

N.A. Filroze, research fellow of the laboratory of storage and agriculture, ARRIVG-FSBSI FSVC.

E-mail: Suburban_Chevrolet@mail.ru L.M. Sokolova, $P h D$, senior research fellow, department of breeding and seed production, ARRIVG-FSBSI FSVC E-mail: Isokolova74@mail.ru

A.V. Kornev, PhD, research fellow, department of breeding and seed production, ARRIVG-FSBSI FSVC. E-mail: alexandrvg@gmail.com

Summary. As a result of a five year research (2013-2017) found that the most promising domestic varieties for prolonged storage are: Marishka, Russian odnosemyannaya, Fortuna, Demetra, Bordovaya VNIIO, Bordeaux 237. Among Dutch hybrids can distinguish $\mathrm{F}_{1}$ Pablo and $\mathrm{F}_{1}$ Vodan. These varieties and hybrids as a result $6-7$ months of storage have a minimal loss of weight loss products and disease and saved high quality of products.

Keywords: red beet, varieties, hybrids, storage, keeping, quality. 